This item was submitted to Loughborough's Research Repository by the author.

Items in Figshare are protected by copyright, with all rights reserved, unless otherwise indicated.

\title{
Exploring the role of social capital in community-based physical activity: qualitative insights from parkrun
}

PLEASE CITE THE PUBLISHED VERSION

https://doi.org/10.1080/2159676X.2017.1376347

\section{PUBLISHER}

(c) Taylor \& Francis

\section{VERSION}

AM (Accepted Manuscript)

\section{PUBLISHER STATEMENT}

This work is made available according to the conditions of the Creative Commons Attribution-NonCommercialNoDerivatives 4.0 International (CC BY-NC-ND 4.0) licence. Full details of this licence are available at: https://creativecommons.org/licenses/by-nc-nd/4.0/

\section{LICENCE}

CC BY-NC-ND 4.0

\section{REPOSITORY RECORD}

Wiltshire, Gareth, and Clare Stevinson. 2019. "Exploring the Role of Social Capital in Community-based Physical Activity: Qualitative Insights from Parkrun”. figshare. https://hdl.handle.net/2134/27222. 
Exploring the role of social capital in community-based physical activity: qualitative insights from parkrun.

Gareth Wiltshire, University of Bath, UK; Clare Stevinson, Loughborough University, UK.

Qualitative Research in Sport, Exercise and Health.

Please note, this pre-publication version may be subject to minor changed in the publishing process.

Citation: Wiltshire, G., \& Stevinson, C. (2017). Exploring the role of social capital in community-based physical activity: qualitative insights from parkrun. Qualitative Research in Sport, Exercise and Health, 1-16. 


\begin{abstract}
There is a need to address social inequalities related to health and physical activity. Taking a practice-led approach to intervention research, this paper uses the case of parkrun - a rapidly growing weekly running initiative - to explore the potential of free, community-based opportunities to improve physical activity in low socioeconomic groups. Our approach departs from individualistic behavioural research and draws on the concept of social capital in order to add to the sociological understanding of physical (in)activity. Interviews were carried out with previously inactive parkrun participants and were analysed thematically through the lens of social capital. Our analysis illustrates how: (1) participants often draw on existing social ties (family, friends, neighbours and colleagues) to initiate their participation in parkrun, (2) participants invest in and benefit from the aggregate labour of the wider parkrun community (their network of social relations) and therefore are privy to significant practical and affective support, and (3) participants utilise acquired social capital to accumulate cultural capital related to injury management, performance and health. These findings add qualitative insight to existing literature highlighting social capital as a key resource in the initiation and maintenance of physical activity. In the on going effort to provide viable physical activity opportunities for low socioeconomic groups, we optimistically argue that volunteer-led, community-based initiatives have the capacity to mobilise resource through social networks. However, in the context of persistent socioeconomic inequalities, it is likely that relying on existing social capital to promote health-enhancing behaviour will limit the impact of this approach.
\end{abstract}

Keywords: Social capital; health; physical activity; parkrun; inequalities. 


\section{Introduction}

A substantial literature base demonstrates that significant health inequalities exist across Western societies resulting in socioeconomic disparities in disease prevalence and lifeexpectancy (Marmot, 2015; Dorling, 2013; Buck and McGuire, 2015). Given the wealth of evidence highlighting the health benefits of physical activity (Lee et al., 2012; O’Donovan et al., 2010; Warburton et al., 2006) it is important to note the role that physical activity might play in shaping these health inequalities. It is therefore concerning that research consistently shows that physical activity is significantly affected by socioeconomic status (Elkaheem et al., 2017; Henning-Broderson et al., 2007; Stalsberg and Pederson, 2010) and that this social gradient is exaggerated in leisure-time (Gidlow et al., 2006). As such, there is a need to better understand how these inequalities are shaped and a need to research potential practical and policy solutions. A number of population wide campaigns exist that attempt to raise citizens' awareness of the health risks associated with physical inactivity (see, for example, Designed To Move in the U.S, Change4life in the UK, Get set 4 life in Australia and Eat Move Live in New Zealand). However, not only have these campaigns failed to significantly reduce physical inactivity, they have received criticism for invoking individual responsibility for lifestyle behaviours while ignoring socioeconomic conditions (Piggin, 2012; Lee et al., 2011). Indeed, the behavioural research that dominates the interventionist physical activity literature has shown little success beyond controlled settings (Müller-Riemenschneider et al., 2008) and has been much criticised for ignoring the social contexts in which health is practiced (Cohn, 2014; Blue et al., 2016). Additionally, while area-based policy interventions committed to reducing spatial disadvantages in deprived communities are, of course, launched with the best of 
intentions, research has shown that they can drift from initial aims and actually exacerbate inequalities in access (Williams, 2017).

There is a strong case to argue that the increasingly popular running initiative, parkrun, is worthy of research investigating physical activity and health inequalities. According to its website, parkrun is an organisation that offers free, weekly, timed running events around the world (parkrun, 2017). The majority of events take place in public parks at 9 am on Saturday mornings and are intended to be inclusive of all abilities. Amid calls for 'practice-led' research involving initiatives that have shown sustained success in real-world settings (Ries et al., 2016), our interest in parkrun is due largely to its impressive growth in recent years having grown from taking place in one park in the UK in 2004 to now taking place in over 1000 locations across 14 countries. Over 2 million registered participants have completed over 22 million runs in total so far (parkrun, 2017). Although research into mass running events already exists (Sato et al., 2015; Scheerder et al., 2015; Sutton, 2010; Lane et al., 2015; Lane et al., 2010; Shipway and Holloway, 2010), we argue that research into parkrun is warranted because the weekly activities are free for participants (events are locally organised by volunteers) and take place in community settings (most often public parks) therefore reducing commonly cited financial and geographic barriers to physical activity in low socioeconomic groups (Ball et al., 2009; Story et al., 2008; Azzarito and Solomon, 2005). Indeed, research into parkrun can contribute to the growing literature base investigating community-based physical activity interventions (Bauman et al., 2009; Bock et al., 2014) from the perspective that health is best enacted in individuals' 'natural' lived settings and involves a complex interplay between individuals' social, cultural and physical environments (Brand et al., 2014). 
Besides some published testimonials about parkrun from medical professionals (Masters, 2014; McCartney, 2015) as well as academic commentaries (Pringle and Pickering, 2015; Turocy, 2016; Weed, 2016; Fullagar, 2016), little research has been published on the organisation and its participants. One study (Stevinson et al., 2015) has shown that participants value the accessibility and inclusivity of events, contributing to initial attendance and sustained involvement. This is perhaps unsurprising given that the event is free to take part in - making it relatively uncommon in the context of other physical activity opportunities such as gyms, leisure centres and commercial running races - and explicitly advertised as being "for everyone” (parkrun, 2017) - helping to avoid the long-standing criticisms of sport as being for the privileged few (Crawford, 1980; Kirk and Colquhoun, 1989). It is interesting to note that participants in Stevinson et al.'s (2015) study also valued the 'community' aspect of parkrun and the dual opportunity for personal gain and for helping others through volunteering and offering support. However, while Stevinson and Hickson (2014) suggest that parkrun has a tendency to appeal to groups with low physical activity such as women, older adults and overweight individuals, its success with low socioeconomic groups is less clear. As such, there is a need to explore the mechanisms and processes that help explain participation patterns. The focus of this paper, therefore, is to investigate the processes that manifest in socioeconomic disparities and to gain a better understanding of parkrun specifically as a potential model for addressing inequalities in physical activity and health.

Our approach departs from individualistic behavioural research and speaks to the need to understand health from a 'social practice' approach (Baum and Fisher, 2014; Nettleton and Green, 2014). In doing so, we respond to Das and Horton's (2012) call to take more consideration of the social environments in which physical activity takes place. While there are 
numerous studies that investigate physical activity promotion as it is related to sociological phenomena, researchers often adopt a somewhat positivistic approach (e.g. Martin et al., 2014) characterised by an emphasis on measurable (usually quantified) data, hypothesis testing and objective interpretation. While many qualitative studies exist (e.g. Hamilton and White, 2014; Eley et al., 2014; Eyler et al., 2014), there is a surprising neglect of social theory incorporated into analyses. We draw influence from Guell et al.’s (2012) attempt to address this in their study on active commuting in which they argue that social theory can capture the complexity that is integral to our understanding of the "social world and the practices and relationships that shape it” (p.234). To investigate how patterns of physical activity are shaped by the social world, we turn to the concept of social capital. Given the wide use of social capital in a broad range of disciplinary contexts, we consider it important in exploring how it may be implemented in physical activity research.

\section{Social capital and physical activity}

There has been an exceptional growth in the social capital literature since the late 1980s (Kawachi et al., 2008) and, generally speaking, authors have used versions of social capital derived from either Robert Putnam or Pierre Bourdieu. Putnam's conceptualisation lends itself to an explicit analyses of social ties related to 'bridging' and 'bonding' (see Putnam, 1995; Field, 2003; Jarvie, 2003). In doing so, Putnam essentially provides a framework for understanding how interpersonal trust and norms of reciprocity facilitate collective action - in the case of bonding social capital (Lindstrom et al., 2011) - and how individuals can use social ties to gain access to opportunities - in the case of bridging social capital (Portes, 1998). By deploying a monetary metaphor, social capital evokes notions of resource and ultimately 
permits us to make judgements about the relative 'wealth' of individuals and groups. There is strong evidence to suggest that health and social capital are strongly related and that social capital contributes to health inequalities (Stephens, 2008; Rothon, et al., 2012; Ferlander, 2007). According to Kawachi et al. (1999) individuals in areas of low social capital have poorer health even when controlling for low income, low education, lack of access to health care, smoking and obesity. Indeed, Putnam (2001) consolidates this idea by concluding that health risks are significantly reduced as a result of improved social connectedness even when individual-level risk factors are controlled for.

While the relationship between social capital and health appears to be well established, the research attending to physical activity is only emerging. Again using Putnam’s framework, Ueshima et al.'s (2010) survey of 2260 participants in Japan found that higher bridging and bonding social capital were associated with lower odds of being physically inactive. Another multi-level study, Ball et al. (2010) measured the associations between physical activity and individual and neighbourhood characteristics and demonstrated that women who participated in local groups or events and women living in neighbourhoods where residents trusted one another, were more likely to participate in leisure-time physical activity. Furthermore, when exploring the relationship between physical activity, social capital and socioeconomic status, Lindstrom et al. (2001) highlighted that poor social participation was one of the strongest predictors of low physical activity of the variables studied and therefore suggest that some of the socioeconomic differences in leisure-time physical activity are due to differences in social capital between socioeconomic groups.

In the context of recent policy objectives to use sport as a vehicle for social cohesion and development, numerous authors have investigated social capital in relation to how it can be 
built and created through sporting initiatives (Adams et al., 2017; Groeneveld et al., 2010; Nicholson and Hoye, 2008; Lawson, 2005). While this present study focuses not on how to build social capital but instead on how social capital is mobilised to improve participation, it is important to note that these processes are not linear or unidirectional. It has been claimed that the volunteering aspect of sporting engagement appears to foster social capital through increasing social and community connectedness is various ways (Harvey et al., 2007; Kay and Bradbury, 2009; Davis-Smith et al., 2002; Peachey et al., 2013) although this finding is highly contingent on context. Indeed, although the relationship between sport and social capital appears to be relevant, it is important to note the critical perspectives offered by Tonts (2005), Morgan (2013) and Collins (2008) who suggest that social capital developed through sport can be fragile and context specific and therefore claims about its social and political worth ought to be modest.

While these studies are illuminating, we take note of Ball et al.’s (2010) claim that little is known about the causal mechanisms underlying the associations between physical activity and social capital and therefore this paper aims to move towards a more detailed microsociological account of how social capital contributes to physical activity and in what circumstances. In this paper we draw more heavily on Bourdieu's social capital and, indeed, see value in engaging in his wider theoretical framework. In doing so, we agree with Whitley (2008, p.112) in that public health research has focused "too narrowly on Putnam's 'communitarian' conceptualization of social capital, to the detriment of Bourdieu's formulation of social capital as a 'credential' by which individuals and groups can buy into positive benefits". For Bourdieu, social capital can be succinctly described as "the aggregate of the actual or potential resources which are linked to possession of a durable network of more or less 
institutionalized relationships of mutual acquaintance and recognition - or in other words, to membership in a group”' (Bourdieu, 1986, p.248). Thus, Bourdieu's approach assumes a 'network' approach and ultimately emphasises that connections to other members in a network allow access to resources that otherwise would not be available. Yet, by foregrounding Bourdieu we do not dismiss research that draws on Putnam but rather we share Carpiano's (2006) view that the two approaches can be reconciled by virtue of pertaining to different parts of the broader social process.

Importantly, by being part of his wider conceptual framework we find that Bourdieu's social capital offers greater appreciation of the material and symbolic complexities of the social world. By thinking of capital as existing in different interconnected forms (social, economic and cultural), Bourdieu argues that capital can be converted and exploited in different ways in certain social and institutional conditions (Bourdieu, 1986). Cockerham's (2005; 2013) health lifestyles theory develops this idea and claims that the combination of these three forms of capital shape the formation of "collective patterns of health-related behaviour" (2005, p.55). Not only does this idea speak to Gatrell et al.'s (2004) suggestion that social capital is related to health due to the role of economic capital, but also - perhaps more subtly - social-class related cultural resources interact with economic and social capital in the social structuring of people's health chances and choices. As Abel (2008, p. 3) illuminates,

[s]haring similar values, knowing how to approach other members properly, the ability to use appropriate language and communication styles are examples of non-material conditions and cultural techniques required for people to enter those networks. Once a member, cultural resources may also facilitate an individual's use of social capital for health gains.

While Abel's research addresses health behaviours more broadly, it is worth pointing out that cultural capital as it relates to physical activity might require specific attention in itself. 
Cultural capital within sport, exercise and physical activity is sometimes simply equated with 'ability’ (Kingsley et al., 2017; Evans and Penney, 2008) but often described through Shilling’s (2003; 2010) 'physical capital' whereby privilege, power and status are attributed to some bodies over others (Hay and MacDonald, 2010; DeLuca, 2013). Cultural capital is context dependent, operating within what Bourdieu calls 'fields', which is crucial to note because different fields define what counts as cultural and physical capital differently and therefore will affect access to social capital in different ways. Although the relevance of cultural capital in gaining access to physically active practices has long been recognised in sporting contexts (Bourdieu, 1977; 1984) and through middle-class aspects fitness and exercise (Smith-Maguire, 2002), we are interested in investigating how this process plays out in an initiative like parkrun that overtly promotes itself through the rhetoric of inclusivity; "it's for everyone” - whatever your cultural or physical capital.

Furthermore, there is utility in exploring a Bourdieusian analysis of social capital because it permits an implicit assumption that social ties impact individuals' intentions and inclinations to engage in physical activity more broadly. With the concept of 'habitus', Bourdieu attempts to clarify how everyday actions are shaped by individuals' unconsciously driven 'schemes of thought' and embodied dispositions (Bourdieu, 1977; 1980; 1984). As such the system of dispositions through which individuals 'choose' whether to engage in physical activity or not is in alignment with the probability of realising such ambitions (Cockerham, 2005). While the focus of this paper is the role of social capital, habitus is necessary to mention because parkrun is only one context in which physical activity is enacted so it is important to consider how and why experiencing parkrun might lead to a lasting relationship with physical activity. Habitus has been explored in this way in other sport-related literature (Kay and 
Laberge, 2002; Brown, 2006) and essentially provides a theoretical basis for understanding what has become "durable" (Bourdieu and Wacquant, 1992, p.133) and transposable "beyond the limits of what has been directly learnt” (Bourdieu, 1984, p.166).

\section{Methods}

This paper draws on data from 20 interviews collected as part of a wider project on the public health potential of parkrun - a mass-running initiative that offers free, weekly, timed running events around the world. While other mass-running initiatives exist, parkrun was of particular interest because it has undergone significant and sustained growth since its inception in 2004. Ethical approval was granted at institutional level and the project was supported by parkrun as a partner organisation. The wider project involved a survey of 7308 parkrun participants recruited via a link in the weekly parkrun news e-mail. The survey aimed to capture the demographic characteristics of participants as well as their health status, physical activity levels and some broader outcome measures of the impact of parkrun [Anonymised]. To explore what parkrun participants valued about the initiative, 48 individuals across the spectrum of participation took part in a nested qualitative phase. Participants for this phase were identified and invited to take part by e-mail based on a sampling matrix using age, gender, running experience, and geographic location. Recruitment continued until our sample reached a target quota of 48 within which these characteristics were fairly represented. As sample sizes in qualitative research are highly contested (Robinson, 2014; Boddy, 2016), the adequacy of this sample was re-assessed following data collection and deemed to be sufficient by virtue of the recurrence of emerging common themes and the richness of the data as judged by the researchers. Analysis of this phase demonstrated that participants valued the accessible, 
inclusive ethos, achievement opportunities, and inherent social support, along with the outdoor natural settings, and integrated volunteer system [Anonymised].

Given the public health focus of the project as an attempt to understand how inactive individuals can engage in more physical activity, this current paper further examines data from the 20 of the 48 participants involved in the qualitative phase who had little or no running experience prior to attending parkrun. The sample analysed for this paper, therefore, included 11 females and 9 males from 17 different UK parkrun locations, aged between 27 and 63 years, all of whom reported that they were inactive before attending parkrun. Index of Multiple Deprivation (IMD) quartiles were used as an indication of the socio-economic status of participants based on their household address. This indicator suggested that our sample was socio-economically diverse with 2 living in the most deprived quartile in the UK, 5 from the $2^{\text {nd }}$ most, 7 from the $2^{\text {nd }}$ least and 2 from the least deprived (4 participants did not provide this information).

Following Bourdieusian research, we recognise the need (and value) of both qualitative and quantitative methods and their ability to ask/answer different kinds of questions (Patulney et al., 2007). In this context, qualitative methods, we argue, have the potential to reveal not only the richness and complexity of the social world (Denzin and Lincoln, 2011) but also to illuminate how social processes are enacted in everyday interactions - processes that larger quantitative studies necessarily omit. In making this claim, we align our study with a number of scholars who have qualitatively investigated social capital across a variety of health behaviours using interviews (Kirst, 2009; Manton et al., 2013; Kay and Bradbury, 2009) and ethnography (Stephens, 2008). To accommodate geographical limitations, semi-structured interviews were conducted by telephone. While we are aware of the relative advantages of conducting 
interviews face-to-face - such as the improved ability to build rapport in a more 'natural' interaction (Shuy, 2003) - we remain confident that telephone interviews have significant virtues (Irvine et al., 2012) and provided sufficient opportunities for participants to articulate their experiences in detail. Interviews were conducted by an experienced qualitative researcher (first author) who asked a range of questions related to the parkrun experience following an interview guide (see Table 1.). The interview guide was developed by two researchers (both authors) and was informed by relevant contemporary research related to physical activity promotion as well as exploratory interests related to parkrun specifically. Given the exploratory nature of the study, participants were also given opportunities to talk freely about their experiences. After the interview audio was transcribed verbatim and anonymised, the corpus of data (consisting of 74,168 words) was imported into NVivo 9 for management and analysis.

\section{[INSERT TABLE 1 AROUND HERE]}

Data were thematically analysed by the same researcher who conducted the interviews which allowed for greater immersion, familiarisation and recall of conversations as is often required in qualitative analysis (Sparkes and Smith, 2013). The stages of analysis were similar to established thematic analysis protocols (see Braun and Clark, 2006; Guest and MacQueen, 2012) and initially included reading transcripts for familiarisation, carrying out iterative inductive coding and establishing abstracted themes. After having identified social capital as an emerging concept, analysis then involved a reductionist and deductive (theory driven) process of coding data related to social capital specifically. During this stage, inspiration was drawn from Jackson and Mazzei’s (2013) metaphore of ‘plugging in’, whereby the analysis process must allow one 'text' (the data) to connect with and speak to another 'text' (the concept of social capital). Working within this framework encouraged the analysis to avoid 
descriptive reproduction of social capital and instead allowed the interpretation to take shape through mutual connections between participants' descriptions of parkrun and existing theory. As a result, data were organised into three themes; (1) social capital as access to opportunity, (2) 'buying-in' to material and affective labour, and (3) social capital as access to cultural capital. These themes were critically scrutinised by a second experienced qualitative researcher for internal validity and finally further reduced when repetition occurred.

As a point of reflection, it is also important to make the epistemological point that the findings of this study are, to some extent at least, co-constructed through the entangled interrelationship between data, theory and ourselves as interpretive researchers (Alvesson and Skoldberg, 2009). This important to note in this paper specifically because of our personal interest and involvement in parkrun as participants and volunteers and also because of our longstanding engagement in the practice of running. Due to both authors' generally positive disposition towards running, we made conscious efforts to be critically reflexive about our subject positions in order to avoid imposing our perspectives on the study. Through being critically reflexive throughout, we feel that our personal involvement with parkrun served not to disrupt but instead to enhance our study design and interpretation by offering a route to connect the data with our own on-going experiences within the situated research context.

\section{Social capital as access to opportunity}

According to Bourdieu (1986), individuals make use of social capital through mobilising social ties in order to gain access to resources and opportunities. For the participants in this study, social ties were valuable in initiating parkrun participation and were mobilised through often incidental and mundane interactions. We consider this important to report as 16 
out of the 20 participants described their initial participation to have been facilitated through existing social ties or 'word of mouth' (see Table 2.). For many, their spouse initiated their first attendance. As Hazel simply explained;

My husband thought it'd be a good idea. He runs quite a lot. He's done marathons and all sorts and he signed me up and said "You're coming," and I'd never run before, so I wouldn't have done it without him kind of encouraging me.

Similarly, other family members played a role. For Elinor, it was her daughter ("My daughter said to me “Come on mum, why don’t you try and do it with me?”) and for Bonnie it was her Dad (“Through my dad really. He’s been doing it for a while”). Beyond family members, several participants cited friends as the key social ties informing and encouraging their first attendance to the event. For example, Kerry noted, "there's one of my friends that comes every week” and Henry said, “a couple of my friends” already attend. Despite being rather prosaic, these repeated examples in our data point to the existence of a tendency towards participation being initiated through immediate social ties. By virtue of being invited or encouraged to attend, newly active participants are benefiting from the network of social relations that they possess prior to becoming active - a benefit that individuals without social ties to parkrun, or indeed with low social capital more generally, are less likely to be have. This data raises a fundamental concern in that lower socioeconomic groups have been shown to have lower levels of social capital through lack of civic engagement and poor neighbourly relations (Li et al., 2005; Li et al., 2008) and therefore are less likely to encounter (intentionally or serendipitously) the mundane, incidental, everyday interactions that seem to have lead the participants in our study accessing a health enhancing opportunity.

[INSERT TABLE 2 AROUND HERE] 
The cyclical and reproductive nature of this process was highlighted by participants describing how, after being introduced to the event, they in turn introduced others to the event. Quite simply, “we’ve obviously subsequently introduced quite a lot of people to the parkrun as well. So it is the word of mouth thing to encourage you along” (Matt). Similarly, James gave an example of this process in relation to colleagues by saying, "I've encouraged people from my office here to go along and there's about half a dozen or so go now”. Indeed, Julia noted that she had invited family members and friends; "I go every week and from that quite a lot of my family members and friends have also joined." While it remains unclear how people are 'encouraged' or 'invited' to attend, it seems that some work is likely to be required. Diane talked about how her son needed "a bit of talking round to get him into it" and Julia mentioned that it was due to the fact that she "kept ranting on about this parkrun on a Saturday morning". Nevertheless, our data point to the notion that parkrun participants are likely to be socially connected to parkrun prior to attending and that those individuals may, in turn, mobilise other existing social ties to invite and encourage others in their network to attend.

Further, as Matt claimed, knowing people already at the event was important to "just ease you in”. Indeed, Kayleigh said, “I wasn’t nervous about going along because I know a number of people that did it anyway and I went with a friend.” As an important reminder of the interactive capacities of forms of capital, the process appeared to be not only linked to having social ties with someone who is a parkrun participant, but also someone who possessed cultural and physical capital in the field of sport and exercise. For Kylie, "I heard about it from a friend who had done it a few times and she was very into running." Of course, the significance of social capital not only depends on the number of connections but, crucially, access to the 
cultural capital related to health and physical activity (running more specifically) that social connections can mobilise. As Bourdieu (1986, p.52) notes;

The volume of the social capital possessed by a given agent thus depends on the size of the network of connections he can effectively mobilize and on the volume of the capital (economic, cultural or symbolic) possessed in his own right by each of those to whom he is connected [sic].

For this reason, being connected to people who are "very into running" or indeed possess the know-how and confidence to feel comfortable in physically active settings appears to be important.

Furthermore, several participants recognised parkrun as an opportunity to develop one’s social network in varying ways. New participants did initially perceive the existence of "cliques" as described by Julia but strongly asserted the tendency of people make newcomers feel welcome. From Matt’s perspective; “if you see somebody who you haven’t seen before you might wander up to them and say hello and “Do you know where you're going?” type thing”. Similarly, Julia said, “if we see somebody else who's stood on their own we'll talk to them and make them feel welcome so they don't feel like they're stood out on a limb”. In light of these kinds of interactions it is possible to suggest that parkrun could be a place to create and build social capital between participants as has been shown to be possible in other sports-related programmes (Adams et al., 2017). This was evident for several participants in the study. As Harry explained;

you know, you turn up, you do the race and you sit around and drink coffee and do whatever afterwards and get to meet a whole bunch of other runners and, you know, some you know to nod to and a few of them you know reasonably well and some acquaintances that you've known over the years kind of congregate together. 
Additionally, Ben talked about re-connecting with old social networks through parkrun which led to participating in more physically active opportunities outside of parkrun. He stated quite simply, "the only reason we ever met up is through parkrun." While our earlier concerns regarding how social capital may reproduce patterns of inequality remain pertinent, these extracts suggest that social capital could be transformative through helping develop social capital once participants do attend.

\section{'Buying-in' to material and affective labour}

An import aspect of social capital is the likelihood that members of a group benefit from the accumulation of the labour of other members of the group. As such, individuals have greater access to resources than they otherwise would have if they were isolated and unconnected. For parkrun, this aspect of social capital most obviously plays out in the practical labour of event volunteering (announcers, time-keepers, course marshals etc.) which provides the necessary resources and support for the events to go ahead. Importantly, this is understood by participants themselves as labour that, effectively, replaces monetary exchanges that are otherwise expected in other forms of physical activity. Most clearly, Ben said, "I know how much it costs to do half marathons... I mean I've signed up for the marathon this year, later on in the year. I've done half marathons this year and it cost me $£ 47$ for one of them." Indeed, Robert said "I'd be willing to pay [for parkrun]. I mean, I'm astounded that it’s free.”

In addition to the practical labour carried out at parkrun events, our data also reveal that participants drew heavily on the collective group for emotional support. Given the wellestablished understanding of the power of social support in physical activity (Eyler et al., 1999; 
Duncan et al., 2005) we feel that this 'affective labour' warrants attention in the context of social capital. Our data illustrate how important this labour was to participants in several ways. For example, Emma said, "I think I was like third last or something and, you know, everybody was cheering at the end and giving you a round of applause and stuff because you'd made it round." This was described in terms of "camaraderie" by Henry and "supportive” by Emily. This work seems to be done by marshals as well as other runners. For Robert;

As you're going round, the marshals give encouragement and we encourage people as they're going round, give them a clap and whatever saying "Come on, you can do it!" and whatever. And people who are struggling we'll tag onto somebody and say "Come on, you can do it!” and things like that.

While the importance of social support for maintaining physical activity is already well documented, we argue that these data highlight new ways that social support can be a resource accessed through social capital in a reciprocal community context. Bonnie's example of affective labour from a stranger highlights how benefits are seen as being afforded indiscriminately to the group members;

I remember that there was a woman on kind of one of the last laps of it when I was obviously struggling and she kind of, you know, supported me through the last lap, which was really nice. I mean I didn't know her and people do that all the time - you know, encourage people, complete strangers, but everybody's kind of there and there is a spirit of it to encourage people.

Even though these kinds of transactions are likely to be similarly experienced in sports clubs where volunteer labour is already commonplace, we argue that the conditions of exchange are markedly different because membership of the parkrun network can be meaningful despite relying on altogether more transient and less committed relationships. In contrast to the highly bonded, homogenous social networks (Morgan, 2013) and the presence of well-connected 
'stalwarts' (Collins and Nichols, 2005) within sports clubs, the sheer number of participants at parkrun events (typically between 200 and 400) reduces the likelihood of strong group bonds emerging. Indeed, while our data is consistent with previous qualitative research into social capital that notes how this support can help develop a sense of 'community' (Manton et al., 2013), we would add that in this context supportive gestures and interactions can usefully be conceptualised as labour. Moreover, the notion that affective labour is offered and received throughout the network of relations at parkrun can be seen as collective profits reinforced through group solidarity. Bourdieu makes this point by saying, "the profits which accrue from membership in a group are the basis of the solidarity which makes them possible” (Bourdieu, 1986, p.51/52). In this way, we argue that parkrun participants realise the benefits of affective labour - in addition to the practical labour - that are available to the members of the network of relations.

These data point to an understanding and appreciation for the value of volunteer labour and it's ability to reduce financial demands on engaging in physical activity. As our interest is in exploring how community-based physical activities may contribute to improving health for low income groups, we suggest that this represents some cause for optimism. However, as we develop our analysis of social capital in parkrun, it is crucial to note that participants in our study did not simply reap the benefits of the labour of the group unconditionally, but rather recognised that they too would need to invest in the group if they were to continue to benefit from it. In this way, when Richard noted; "I'll tell you the other thing to it is the volunteers. You've got to give them credit," his use of the metaphor 'credit' was telling. Bourdieu (1986, p.51) recognised that networks of relationships, "provide each of its members with the backing of the collectively-owned capital, a 'credential' which entitles them to credit, in the various 
senses of the word." Here, not only do participants feel gratitude but also a sense of debt to the volunteers (and the group in general). As Patesh put it;

Nobody asks you for any money and without volunteers, you know, something as great as this just wouldn't exist and you need to recognise that. I feel quite passionately that my next time there I am going to volunteer and not run and then the following time I'll run after that.

This sense of debt and expectation to reciprocate was a key way that parkrun was understood by the participants in our study. Zara's understanding of volunteering as an expectation was fairly typical; "they depend on volunteers so, you know, I try and do my bit". Again, for Ben; "For me, volunteering is about giving it back to people who are just starting out and if it's not there for them they might not run.” For others, volunteering was a convenient alternative to running when they weren't able to take part through injury; "I think I've volunteered quite a few times when I've had an injury. So I kind of think “Well, if I can’t run I might as well volunteer" " (Zara). That said, it was also interesting to note that some participants in this study talked of volunteering as a way of "giving back" and something that is beneficial for "everyone involved" (Bonnie). Yet, Craig was more overtly selfish in his description of volunteering;

It's not something I think, “Oh, I don't really want to have to volunteer, but I should do.” You know, I do it because I want to because in a way I'm kind of doing it for myself because most weeks I do it there's somebody else doing it for me. So it’s kind of like doing it for yourself in a way.

When participants had not volunteered, there was a sense of guilt for not doing so. Bonnie said that volunteering is something that she "should" do and Henry noted, "well, I've been very bad because I've only done it once.” In Bourdieu's terms, this subjective sense of 
gratitude is understood as a condition of being part of the network of social relations. He asserts;

the network of relationships is the product of investment strategies, individual or collective, consciously or unconsciously aimed at establishing or reproducing social relationships that are directly usable in the short or long term, i.e., at transforming contingent relations, such as those of neighbourhood, the workplace, or even kinship, into relationships that are at once necessary and elective, implying durable obligations subjectively felt (feelings of gratitude, respect, friendship, etc.) (Bourdieu, 1986, p52).

For one participant, this understanding of expectation and guilt lead to considering making a monetary donation; "I might even, like, give them some money to assuage my guilt a bit as well because there's a donation thing which I've never used” (Henry). In this respect, our data raises questions about the potential for the parkrun model to reduce inequalities in physical activity participation because social capital and economic capital are interdependent. While the availability of free-time for volunteering is contested for individuals in low socioeconomic groups (Roberts, 2015), the feeling of guilt and responsibility for not being able to volunteer (or able to donate money to 'assuage guilt') may play in a role in disengaging some participants from low socioeconomic groups.

Importantly, these transactions occur through no formal agreement or indeed with any promise that benefits will be equally returned to individuals following their investment. In this way, as Portes (1998, p.4) notes, "relative to economic exchange, they are characterized by less transparency and more uncertainty. For example, transactions involving social capital tend to be characterized by unspecified obligations, uncertain time horizons, and the possible violation of reciprocity expectations.” As such, our analysis suggests that the role of social capital in parkrun represents a markedly different exchange to the transactions that occur in other 
physically active opportunities where users are expected to pay, yet does not entirely alleviate participants from their obligation to contribute labour. So while this exchange is likely to be more favourable than monetary transactions for low socioeconomic participants, it is not true to say that these relationships remove barriers entirely. Participants 'buy-in' to the network through a process of benefiting from the aggregate labour, feeling gratitude/expectation and then contributing to the labour themselves if they have the means to do so.

\section{Social capital as access to cultural capital}

Our data also illustrate that social capital plays a role in acquiring cultural capital that otherwise would not have been acquired by participants outside of the parkrun network. In this context, we are referring to cultural capital as the symbolic resources of skills, competencies and knowledge as they relate to the fields of physical activity, sport and health more generally. While it has previously been found that cultural capital engendered through sports can be a means to form distinctions between social classes (Stempel, 2005) and that higher cultural capital relates to continued engagement with exercise (Engström, 2008), our interest is in how social capital serves to transmit activity-specific cultural capital to new participants as they learn to move in new ways.

Exchanging skills and competences within the network was discussed by several interviewees. More experienced participants were described as being "full of advice and help" (Craig) and this was said too of the volunteers; “if there's anything you need to know there's always somebody there, either one of the volunteers or any of the runners" (Craig). Indeed, for Richard there was a level of surprise; "when we first went down there we weren’t aware of the information you got through. So it's educational, it’s informative”. Other participants who had 
been taking part in parkrun for some time talked about how giving advice to newcomers related to performance, injury management and motivational techniques was about "passing it on" (Kylie). Robert gave some simple examples of passing on performance advice:

I've done the course a few times and there's a few undulations. I'll say "Well this is the downhill, so this is where you open your legs and you go for it," and there's a few hills that you go up and "This is where you need to take a shorter step and lean forward and get into it," and things like that.

Furthermore, knowledge was also exchanged in digital communities in ways that benefited both performance and injury prevention. As Robert continued;

We have our own Facebook group as well so we're passing information. People come on asking for information like "I've got this type of injury. What do you recommend?" or "I want to improve my speed. What do you recommend?" and things like that.

In one case, the exchanging of knowledge was extended beyond running itself towards health more generally. Emma was diagnosed with diabetes and used parkrun to 'educate’ others about prevention;

It's about trying to convert people as well going "Don't wait till it's too late to do exercise.” Because I always thought I was fairly fit and I wasn't that overweight and all that, you know, the risk factors for diabetes, but I ended up getting it anyway. So I'm trying to say to people “No, don't wait till you've been diagnosed with something. Do something now."

By exchanging knowledge within the network we can say that newly active participants develop cultural capital that is sometimes specific to running, and sometimes more generally related to and exercise and health. In practical terms, this capital is likely to be beneficial to participants and may indeed lead to improvements in competence. However, these exchanges also have symbolic value whereby they serve to define who is in the network and what being in 
the network entails. When exchanged in the ways described above, the transmission of cultural capital appears to positively benefit newly active runners, but one interviewee noted that 'insider' knowledge can define the limits of the group in exclusionary ways. James said, "I’ve heard people talking about 'negative splits'. I happen to know what a negative split is, but that sort of thing puts people off and talking about specialised clothing and what have you.”

In spite of this example, the previously inactive participants who constituted the sample of this study overwhelmingly appeared to welcome the advice exchanged at events and began to develop a repertoire of resources that made them feel more at ease in the practice of running itself. Many participants described a transition from a subject position that was uncomfortable with physically active practices to one that was now comfortable. For example, Julia asserted, “[before parkrun] I would never have gone to a $10 \mathrm{~K}$ run because I'd have thought 'Oh, those are proper runners. I'm not'. ” Although rather tentatively, Kayleigh also said, "I can now sort of class myself as a runner". We argue that these extracts point towards the emergence of a ‘sporting habitus' (Engstrom, 2008; Green, 2014) whereby objective conditions of possibility for engaging in physical activity align with participants' embodied inclinations towards it. Interestingly, lacking physical capital imposed some limitations on participants' transition which meant that some preferred to describe themselves as a "jogger" because "I'm too slow to be a runner" (Emily). Indeed, this embodied aspect was experienced by Ben who said, "I'm a big lump. I'm 6 foot 2. I'm not particularly built for running”. Yet, despite lacking the physical capital that appears to be highly valued in the fields of sport and exercise more broadly (Light and Kirk, 2001; Frew and McGillivray, 2005; Stewart et al., 2013) many participants in our study continued to participate and even showed signs of developing a taste for the practice of running evident through engaging in the symbolic and consumer aspects of running. For 
example, Kylie noted, "I do get addicted to going into shops and going 'Oh look, there’s a new pair of runners [shoes] in there!'” and Craig said;

I buy the proper running stuff. I buy the shoes, the clothes, you know, so because I buy the shoes and the clothes and I kind of want to enter the marathons and, you know, I want to do that, so I thought "You know what? Yeah, I am a runner I guess."

While the purchasing of running-related clothing and the financial implications that go with it should not be ignored, none of the participants in our study suggested that engaging in this kind of consumption was important to the accessibility of the practice itself as has been shown to be the case in other physically active practices (Atencio et al., 2009; Smith-Maguire, 2008).

Of course, developing a taste that aligns with the practice of running is not something that requires social capital necessarily and there is no doubt that more solitary runners might develop a habitus through different means. However, we argue that exchanges of cultural capital through networks of social relations was important for the participants in our study precisely because of their deficits in physical capital. From Bourdieu’s perspective (1986, p.52), "exchange transforms the things exchanged into signs of recognition and, through the mutual recognition and the recognition of group membership which it implies, reproduces the group. By the same token, it reaffirms the limits of the group.” In this sense, it is not only the possession of cultural capital but also the process of acquiring it that is important. Once again, these examples illustrate how social processes within parkrun can mobilise the flow of cultural capital to the extent that it is potentially accessible to low socioeconomic groups. The examples given by our participants highlight how competence, know-how and confidence can be developed with individuals who are low in cultural capital through 'passing on' knowledge in 
accessible ways which in turn helps newly active parkrunners feel at ease and in alignment with the practice itself.

\section{Conclusion}

In the context of significant health inequalities, this study set out to contribute to the growing literature investigating the social processes that shape patterns of physical (in)activity. Taking a practice-led approach, we explored the increasingly popular, free, community-based running initiative parkrun to investigate the role of social capital in shaping participation. Our analysis revealed that social capital shapes parkrun participation in three ways. First, participants often draw on existing social ties (family, friends, neighbours and colleagues) to initiate their participation in parkrun. Second, participants invest in and benefit from the aggregate labour of the wider parkrun community (their network of social relations) and therefore are privy to significant practical and affective support. Third, having gained social capital, participants benefit from the flow of cultural capital within the network of relations from which they have access to advice and guidance related to running performance, injury management and health. In our attempt to examine the potential of free, community-based initiatives to address health inequalities, these themes reveal that social operates in both reproductive and transformative ways and should be carefully considered in future health promotion programmes.

Given that running is only one form of physical activity and one which is unlikely to appeal to everyone, it important to acknowledge this limitations of the initiative and focus on the processes that appear to be most salient to its success. Our findings suggest that health promoters aiming to improve physical activity in low socioeconomic groups ought to not only 
employ individualistic behaviour change interventions, but also seek to exploit individuals' social relationships as fruitful sources of support. These data, therefore, advocate in favour of efforts to increase social capital in areas of low socioeconomic status. Indeed, by drawing on social capital in local communities, participants in our study demonstrate how the parkrun model may help reduce the financial and geographic barriers to physical activity that are often experienced in low socioeconomic groups. In light of our findings that suggest that even loose ties with relative strangers can be highly valued, it may be possible for health promoters to more effectively and cooperatively coordinate practical and affective labour especially with the social networking possibilities enabled through the recent growth of digital technologies (Cho, 2015). Furthermore, by suggesting that the parkrun model enables individuals from low socioeconomic groups to benefit from the aggregate labour and exchange of knowledge from the wider parkrun network, we argue that there is call for optimism in addressing physical activity inequalities in the UK and beyond. This is especially important to note as social capital appears to facilitate the growth of cultural capital which might enable physical activity to take place beyond the specific context of parkrun itself.

More critically, however, the findings of this study also speak to the concerns related to the reproduction of health inequalities within contemporary economic and political landscapes. Even with the promotion of free community-based initiatives such as parkrun it is important to note that the objective probabilities of individuals actually engaging in these physical activity opportunities is linked to their social capital which is unevenly distributed across social gradients ( $\mathrm{Li}$ et al., 2005; Li et al., 2008). In the UK, there is evidence to suggest that new social classes are emerging below the traditional working class (Savage et al., 2013) and that in many cases health inequalities have widened in the past 5 years (The Lancet, 2017). As such, 
this study also suggests that - without significant social, economic and political change - relying on social capital to promote physical activity is likely to disproportionately engage individuals from middle-high income groups and thus fail to reduce inequalities. While this perspective is rather pessimistic, at the least this study contributes to demonstrating that physical inactivity in low socioeconomic groups is shaped not by deficits in individual will and self-determination, but by significant wider social forces.

\section{References}

Adams, A., Harris, K., \& Lindsey, I. (2017). Examining the capacity of a sport for development programme to create social capital. Sport in Society, 437(July), 1-16.

Alvesson, M., and K. Skoldberg. 2009. Reflexive Methodology: New Vistas for Qualitative Research. 2nd ed. London: Sage.

Atencio, M., Beal, B., \& Wilson, C. (2009). The distinction of risk: Urban skateboarding, street habitus and the construction of hierarchical gender relations. Qualitative research in sport and exercise, 1(1), 3-20.

Azzarito, L. \& Solomon, M. (2005). A reconceptualization of physical education: The intersection of gender/race/social class. Sport, Education and Society, 10(1), 25-47.

Ball, K., Cleland, V. J., Timperio, A. F., Salmon, J., Giles-Corti, B. \& Crawford, D. A. (2010). Love thy neighbour? Associations of social capital and crime with physical activity amongst women. Social Science and Medicine, 71(4), 807-814.

Ball, K., Timperio, A. \& Crawford, D. (2009). Neighbourhood socioeconomic inequalities in food access and affordability. Health \& Place, 15(2), 578-585.

Baum, F. \& Fisher, I. (2014). Why behavioural health promotion endures despite its failure to reduce health inequities. Sociology of Health and Illness, 36(2), 213-225.

Bauman, A., Murphy, N. \& Lane, A. (2009). The role of community programmes and mass events in promoting physical activity to patients. British journal of sports medicine, 43, 44-46.

Blue, S., Shove, E., Carmona, C. \& Kelly, M. P. (2016). Theories of practice and public health: understanding (un)healthy practices. Critical Public Health, 26(1), 36-50. 
Bock, C., Jarczok, M. N. \& Litaker, D. (2014). Community-based efforts to promote physical activity: A systematic review of interventions considering mode of delivery, study quality and population subgroups. Journal of Science and Medicine in Sport, 17(3), 276-282.

Boddy, C. R. (2016). Sample size for qualitative research. Qualitative Market Research: An International Journal, 19(4), 426-432.

Bourdieu P. (1984). Distinction: A social critique of the judgement of taste. Cambridge, MA: Harvard University Press.

Bourdieu, P. (1977). Outline of a Theory of Practice. Cambridge: Cambridge University Press.

Bourdieu, P. (1980). The logic of practice. Stanford: Stanford University press.

Bourdieu, P. (1986). The forms of capital. In Richardson, D. (ed.), Handbook of theory and research for the sociology of education, pp. 241-258, New York: Greenwood.

Bourdieu, P. \& Wacquant, L. (1992). An invitation to reflexive sociology. Cambridge: Polity Press.

Brand, T., Pischke, C. R., Steenbock, B., Schoenbach, J., Poettgen, S., Samkange-Zeeb, F. \& Zeeb, H. (2014). What works in community-based interventions promoting physical activity and healthy eating? A review of reviews. International Journal of Environmental Research and Public Health, 11(6), 5866-5888.

Braun, V. \& Clarke, V. (2006). Using thematic analysis in psychology. Qualitative Research in Psychology, 3, 77-101.

Brown, D. (2006). Pierre Bourdieu's “Masculine Domination” thesis and the gendered body in sport and physical culture. Sociology of Sport Journal, 23(2), 162-188.

Buck, D. \& Maguire, D. (2015). Inequalities in Life Expectancy: Changes over time and implications for policy. London: The Kings Fund.

Carpiano, R. M. (2006). Toward a neighborhood resource-based theory of social capital for health: Can Bourdieu and sociology help? Social Science \& Medicine, 62(1), 165-175.

Cho, J. (2015). Roles of smartphone app use in improving social capital and reducing social isolation. Cyberpsychology, Behavior, and Social Networking, 18(6), 350-355.

Cockerham, W. C. (2005). Health Lifestyle Theory and the Convergence of Agency and Structure. Journal of Health and Social Behavior, 46(1), 51-67.

Cockerham, W. C. (2013). Bourdieu and an Update of Health Lifestyle Theory. In W. C. Cockerham (Ed.), Medical Sociology on the Move: New Directions in Theory (pp. 127-154). Dordrecht: Springer Netherlands.

Cohn, S. (2014). From health behaviours to health practices: an introduction. Sociology of Health \& Illness, 36(2), 157-162.

Collins, M. and Nichols, G., 2005. Summary - an emerging research agenda. In: G. Nichols and M. Collins, eds. Volunteers in sports clubs. Eastbourne: Leisure Studies Association, 119125. 
Collins, M.F.,(2008). Social exclusion from sport and leisure. In: B. Houlihan, ed. Sport and society: $a$ student introduction. 2nd ed. London: Sage.

Crawford, R. (1980). Healthism and the medicalization of everyday life. International Journal of Health Services, 10, 365-388.

Das, P. \& Horton, R. (2012). Rethinking our approach to physical activity. The Lancet, 380(9838), 189-190.

Davis-Smith, J., Ellis, A., \& Howlett, S. (2002). UK-wide evaluation of the Millennium Volunteers Programme. Research Report No. 357, Institute for Volunteering Research, London.

Deluca, J. R. (2013). Swim club membership and the reproduction of happy, healthy children. Qualitative Research in Sport, Exercise and Health, 5(1), 58-79.

Denzin, N. K. \& Lincoln, Y. S. (eds.) (2011). The Sage handbook of qualitative research. London: Sage.

Dorling, D. (2013). Unequal Health: The Scandal of Our Times, Bristol: Policy Press.

Duncan, S. C., Duncan, T. E. \& Strycker, L. A. (2005). Sources and types of social support in youth physical activity. Health psychology, 24(1), 3.

Eley, R., Bush, R. \& Brown, W. (2014). Opportunities, barriers, and constraints to physical activity in rural Queensland, Australia, Journal of Physical Activity and Health, 11, 68-75.

Elhakeem, A., Cooper, R., Bann, D., Kuh, D. \& Hardy, R. (2017). Birth weight, school sports ability and adulthood leisure-time physical activity. Medicine in Science and Sports Exercise, 49(1), 64-70.

Engström, L.-M. (2008). Who is physically active? Cultural capital and sports participation from adolescence to middle age-a 38-year follow-up study. Physical Education \& Sport Pedagogy, 13(4), 319-343.

Evans, J., and D. Penney. (2008). "Levels on the Playing Field: The Social Construction of Physical 'Ability' in the Physical Education Curriculum." Physical Education and Sport Pedagogy 13 (1), 31-47.

Eyler, A. A., Brownson, R. C., Donatelle, R. J., King, A. C., Brown, D. \& Sallis, J. F. (1999). Physical activity social support and middle-and older-aged minority women: results from a US survey. Social Science \& Medicine, 49(6), 781-789.

Eyler, A., Chriqui, J., Maddock, J., Cradock, A., Evenson, K., Gustat, J., \& Zieff, S. G. (2014) Opportunity meets planning: An assessment of the physical activity emphasis in state obesity-related plans. Journal of Physical Activity \& Health, 1(1), 45-50.

Ferlander, S. (2007). The Importance of Different Forms of Social Capital for Health. Acta Sociologica, 50(2), 115-128.

Field, J. (2003). Social Capital. London: Routledge.

Frew, M. \& McGillivray, D. (2005). Health clubs and body politics: Aesthetics and the quest for physical capital. Leisure studies, 24(2), 161-175. 
Fullagar, S. (2016). Parkrun is an important movement - and should remain free for participants, The Conversation, accessed online on 14/4/2017 at: http://theconversation.com/parkrun-isan-important-movement-and-should-remain-free-for-participants-58097

Gatrell, A. C., Popay, J., \& Thomas, C. (2004). Mapping the determinants of health inequalities in social space: can Bourdieu help us? Health \& Place, 10(3), 245-57.

Gidlow, C., Johnston, L. H., Crone, D., Ellis, N., \& James, D. (2006). A systematic review of the relationship between socio-economic position and physical activity. Health Education Journal, 65(4), 338-367.

Green, K. (2014). Mission impossible? Reflecting upon the relationship between physical education, youth sport and lifelong participation. Sport, Education and Society, 19(4), 357-375.

Groeneveld, M., Houlihan, B., \& Ohl, F. (2010). Social capital and sport governance in Europe. London: Routledge.

Guell, C., Panter, J., Jones, N. R., \& Ogilvie, D. (2012). Towards a differentiated understanding of active travel behaviour: using social theory to explore everyday commuting. Social Science \& Medicine, 75(1), 233-239.

Guest, G., MacQueen, K. M. \& Namey, E. E. (2012). Applied thematic analysis. London, UK: Sage.

Hamilton, K. \& White, K. M. (2014) Strategies for developing and delivering a parental physical activity intervention: answers to the what and how, Journal of Physical Activity and Health, 11(1), 152-164.

Harvey, J., Lévesque, M., \& Donnelly, P. (2007). Sport volunteerism and social capital. Sociology of Sport Journal, 24(2), 206-223.

Hay, P. J., \& D. Macdonald. 2010. "Evidence for the Social Construction of Ability in Physical Education.” Sport, Education and Society 15 (1): 1-18.

Henning-Brodersen, N., Steptoe, A., Boniface, D. R. \& Wardle, J. (2007). Trends in physical activity and sedentary behaviour in adolescence: ethnic and socioeconomic differences. British Journal of Sports Medicine, 41(3), 140-4.

Irvine, A., Drew, P. \& Sainsbury, R. (2013). 'Am I not answering your questions properly?’Clarification, adequacy and responsiveness in semi-structured telephone and face-to-face interviews. Qualitative Research, 13(1), 87-106.

Jackson, A. \& Mazzei, L. (2013). Plugging one Text Into Another: Thinking with theory in qualitative research. Qualitative Inquiry, 19(4), 261-271.

Jarvie, G. (2003). "Sport, Communitarianism and Social Capital: A Neighbourly Insight Into Scottish Sport”. International Review for the Sociology of Sport, 38(2), pp.139-153.

Kawachi, I., Kennedy, B. P. \& Glass, R. (1999). Social capital and self-rated health: a contextual analysis. American journal of public health, 89(8), 1187-1193.

Kawachi, I., Subramanian, S. V. \& Kim, D. (2008). Social Capital and Health. Boston: Springer.

Kay, J., \& Laberge, S. (2002). The 'New' Corporate Habitus in Adventure Racing. International Review for the Sociology of Sport, 37(1), 17-36. 
Kay, T., \& Bradbury, S. (2009). Youth sport volunteering: developing social capital? Sport, Education and Society, 14(1), 121-140.

Kingsley, B. C., Spencer-Cavaliere, N., \& Tink, L. N. (2017). So all kids can play? Looking beyond the rhetoric of an equal playing field. Qualitative Research in Sport, Exercise and Health, 6778(June), 1-17.

Kirk, D. \& Colquhoun, D. (1989). Healthism and Physical Education. British Journal of Sociology of Education, 10(4), 417-434.

Kirst, M. (2009). Social Capital and Beyond: A Qualitative Analysis of Social Contextual and Structural Influences on Drug-Use Related Health Behaviors. The Journal of Drug Issues, 39(3), 653-676.

Lancet, The. (2017). The health inequalities and ill-health of children in the UK. The Lancet, 389(10068), 477.

Lane, A., Murphy, N. \& Bauman, A. (2015). An effort to "leverage" the effect of participation in a mass event on physical activity. Health Promotion International, 30(3), 542-551.

Lane,A., Murphy, N. M., Smyth, P. \& Bauman, A. (2010). Do Mass Participation Sporting Events Have a Role in Making Populations More Active? Research Report 2. Ireland: Centre for Health Behaviour Research, Waterford Institute of Technology and Irish Sports Council.

Lawson, H. A. (2005). Empowering people, facilitating community development, and contributing to sustainable development: The social work of sport, exercise, and physical education programs. Sport, Education and Society, 10(1), 135-160.

Lee, I. M., Shiroma, E. J., Lobelo, F., Puska, P., Blair, S. N. \& Katzmarzyk, P. T. (2012). Effect of physical inactivity on major non-communicable diseases worldwide: an analysis of burden of disease and life expectancy. The Lancet, (July), 9-19.

Lee, J., Piggin, J. \& Sebar, B. (2011). As a matter of “fact”: Change4Life is not as well grounded in evidence-based practice as would be expected. WORD, Journal Of The International Linguistic Association, 0-13.

Li, Y., Pickles, A. \& Savage, M. (2005). Social capital and social trust in Britain. European Sociological Review, 109-123.

Li, Y., Savage, M. \& Warde, A. (2008). Social mobility and social capital in contemporary Britain. British Journal of Sociology, 59(3), 391-411.

Light, R., \& Kirk, D. (2001). Australian Cultural Capital - Rugby’s Social Meaning: Physical Assets, Social Advantage and Independent Schools. Culture, Sport, Society, 4(3), 81-98.

Lindström, M. (2011). Social capital, desire to increase physical activity and leisure-time physical activity: A population-based study. Public Health, 125(7), 442-447.

Lindstrom, M., Hanson, B. \& Ostergren, P. O. (2001). Socioeconomic differences in leisure-time physical activity: The role of social participation and social capital in shaping health related behaviors. Social Science and Medicine, 52(3), 441-451. 
Manton, E., Pennay, A. \& Savic, M. (2013). Public drinking, social connection and social capital: A qualitative study. Addiction Research \& Theory, 6359 (January), 1-11.

Marmot, M. (2015). The Health Gap. London: Bloomsbury.

Martin, K., Bremner, A., Salmon, J., Rosenberg, M. \& Giles-Corti, B. (2014) Physical, policy, and sociocultural characteristics of the primary school environment are positively associated with children's physical activity during class time, Journal of Physical Activity \& Health, 11(3), 553-563.

Masters, N. (2014). Parkrun eases the loneliness of the long-distance runner. British Journal of General Practice, 64(625), 408-408.

McCartney, M. (2015). Combination of exercise and social interaction is why I love parkrun. BMJ, 230 (January).

Morgan, H. (2013). Sport volunteering, active citizenship and social capital enhancement: what role in the "Big Society"? International Journal of Sport Policy and Politics, 5(3), 381-395.

Muller-Riemenschneider, F., Reinhold, T., Nocon, M., \& Willich, S. N. (2008) Long term effectiveness of interventions promoting physical activity: a systematic review, Preventive Medicine, 47, 354-68.

Nettleton, S. \& Green, J. (2014). Thinking about changing mobility practices: how a social practice approach can help. Sociology of Health \& Illness, 36(2), 239-251.

Nicholson, M., \& Hoye, R. (eds.) (2008). Sport and social capital. London: Butterworth-Heinemann.

O’Donovan, G., Blazevich, A.J., Boreham, C., Cooper, A.R., Crank, H. \& Ekelund, U. (2010). The ABC of physical activity for health: a consensus statement from the British Association of Sport and Exercise Sciences. Journal of Sport Science, 28, 573-91.

Parkrun (2017) www.parkrun.org.uk [accessed 29/3/2017]

Patulny, R. V., Lind, G. \& Svendsen, H. (2007). Exploring the social capital grid: bonding, bridging, qualitative, quantitative. International Journal of Sociology and Social Policy, 27(1), 32-51.

Patulny, R., Siminski, P. \& Mendolia, S. (2015). The front line of social capital creation--a natural experiment in symbolic interaction. Social Science \& Medicine, 125, 8-18.

Piggin, J. (2012). Turning health research into health promotion: a study of causality and 'critical insights’ in a United Kingdom health campaign. Health policy, 107(2), 296-303.

Portes, A. (1998). Social Capital: Its Origins and Applications in Modern Sociology. Annual Review of Sociology, 24(1), 1-24.

Pringle, A. \& Pickering, K. (2015) Smarter Running: shaping the behavioural change interventions of the future! Letter to the editor. Perspectives in Public Health, 135(3), 116-117.

Putnam, R. (1995). Bowling Alone: America’s Declining Social Capital. Journal of Democracy, 6, 6578. 
Putnam, R. (2001). Social capital: Measurement and consequences. Canadian Journal of Policy Research, 2(1), 41-51.

Reis, R. S., Salvo, D., Ogilvie, D., Lambert, E. V., Goenka, S. \& Brownson, R. C. (2016). Scaling up physical activity interventions worldwide: Stepping up to larger and smarter approaches to get people moving. The Lancet, 388(10051),1337-1348.

Roberts, K. (2015). Social class and leisure during recent recessions in Britain. Leisure Studies, 34(2), 131-149.

Robinson, O. C. (2014). Sampling in interview-based qualitative research: A theoretical and practical guide. Qualitative Research in Psychology, 11(1), 25-41.

Rothon, C., Goodwin, L. \& Stansfeld, S. (2012). Family social support, community "social capital” and adolescents' mental health and educational outcomes: a longitudinal study in England. Soc Psychiatry Psychiatr Epidemiol, 47(5), 697-709.

Sato, M., Jordan, J. S. \& Funk, D. C. (2015). Distance running events and life satisfaction: A longitudinal study. Journal of Sport Management, 29(4), 347-361.

Savage, M., Devine, F., Cunningham, N., Taylor, M., Li, Y., Hjellbrekke, J. \& Miles, A. (2013). A new model of social class? Findings from the BBC's Great British Class Survey experiment. Sociology, 47(2), 219-250.

Scheerder, J., Breedveld, K., Borgers, J. (2015). Who is doing a run with the running boom? In: Scheerder, J., Breedveld, K., Borgers, J. (Eds.), Running across Europe: The Rise and Size of One of the Largest Sport Markets. London: Palgrave Macmillan, 1-27.

Shilling, C. (2010). "Exploring the Society-body-School Nexus: Theoretical and Methodology Issues in the Study of Body Pedagogics.” Education and Society, 15, 151-167

Shilling, C., 2003. The body and social theory. 2nd Ed. London: Sage

Shipway, R. \& Holloway, I. (2010). Running free: embracing a healthy lifestyle through distance running. Perspectives in Public Health, 130(August), 270-276.

Shuy, R. W. (2003). In-person versus telephone interviewing. In: Holstein, J. A. \& Gubrium, J. F. (eds.) Inside Interviewing: New Lenses, New Concerns, Thousand Oaks, CA: Sage, 175-193.

Smith-Maguire, J. (2002). Body lessons: fitness publishing and the cultural production of the fitness consumer. International Review for the Sociology of Sport, 37(3-4), 449-464.

Smith-Maguire, J. (2007). Fit for consumption: Sociology and the business of fitness. London: Routledge.

Sparkes, A. C. \& Smith, B. (2013). Qualitative research methods in sport, exercise and health: From process to product. London: Routledge.

Stalsberg, R. \& Pedersen, A. V. (2010). Effects of socioeconomic status on the physical activity in adolescents: A systematic review of the evidence. Scandinavian Journal of Medicine and Science in Sports, 20(3), 368-383. 
Stempel, C. (2005). Adult Participation Sports as Cultural Capital: A Test of Bourdieu's Theory of the Field of Sports. International Review for the Sociology of Sport, 40(4), 411-432.

Stephens, C. (2008). Social capital in its place: using social theory to understand social capital and inequalities in health. Social Science \& Medicine, 66(5), 1174-84.

Stevinson, C. \& Hickson, M. (2014). Exploring the public health potential of a mass community participation event. Journal of Public Health, 36, 268-74.

Stevinson, C., Wiltshire, G. \& Hickson, M. (2015). Facilitating Participation in Health-Enhancing Physical Activity: A Qualitative Study of parkrun, International Journal of Behavioral Medicine, 22, 170-177.

Stewart, B., Smith, A. \& Moroney, B. (2013). Capital building through gym work. Leisure Studies, 32(5), 542-560.

Story, M., Kaphingst, K. M., Robinson-O’Brien, R. \& Glanz, K. (2008). Creating healthy food and eating environments: policy and environmental approaches. Annu. Rev. Public Health, 29, 253-272.

Sutton, C. (2010). Embodying a Healthy Running Body in a British Non-Elite Road Running Community. In Ettorre, E. (ed.) Culture, Bodies and the Sociology of Health. London: Routledge. 63-81.

Tonts, M. (2005). Competitive sport and social capital in rural Australia. Journal of Rural Studies, 21(2), 137-149.

Turocy, T. (2016). The Behavioural Economics of Parkrun, UAE ECO Blog, accessed online on 14/4/2017 at: https://ueaeconomics.wordpress.com/2016/04/22/the-behaviouraleconomics-of-parkrun/

Ueshima, K., Fujiwara, T., Takao, S., Suzuki, E., Iwase, T., Doi, H. \& Kawachi, I. (2010). Does social capital promote physical activity? A population-based study in Japan. PLoS ONE, $5(8)$.

Warburton, D. E. R., Nicol, C. W. \& Bredin, S. S. D. (2006). Health benefits of physical activity: the evidence. Canadian Medical Association Journal, 174(6), 801-809.

Weed, M. (2016). What's parkrun worth? ProfMikeWeed, Accessed online on 14/4/2017 at: https://profmikeweed.wordpress.com/2016/04/13/whats-parkrun-worth/

Welty Peachey, J., Cohen, A., Borland, J., \& Lyras, A. (2013). Building social capital: Examining the impact of Street Soccer USA on its volunteers. International Review for the Sociology of Sport, 48(1), 20-37.

Whitley, R. (2008). Social Capital and Public Health. In Kawachi, I. \& Submaranian, D. Social capital and health Springer, New York. (95-115).

Williams, O. (2017). Identifying adverse effects of area-based health policy: An ethnographic study of a deprived neighbourhood in England. Health \& Place, 45, 85-91. 
Table 1. Interview guide

Opening topic question

Tell me about your involvement with exercise of the years?

How did you first become involved in parkrun?

\section{Follow up questions}

Were you active as a youngster?

What sort of activities do you generally like and dislike?

Does physical activity matter to you personally?

What led you to first going?

Are these reasons still the same now?

How did you feel on the first occasion?

Any positive outcomes or experiences?

Any negative outcomes or experiences?

How difficult is it to talk to people at parkrun?

Can you tell me about the atmosphere at the events?

How did you get involved with volunteering?

What roles have you been involved with?

What motivates you to volunteer at parkrun? parkrun. 
Table 2. Showing how social relationships facilitated participants' initial attendance

\begin{tabular}{ll}
\hline Informed of parkrun through family member, friend or & Diane (family member) \\
acquaintance already attending & Harry (family member) \\
& Matt (family member) \\
& Bonnie (family member) \\
& Elinor (family member) \\
& Patesh (friend or acquaintance) \\
& Emma (friend or acquaintance) \\
& Ben (friend or acquaintance) \\
& Kylie (friend or acquaintance) \\
& Henry (friend or acquaintance) \\
& Zara (friend or acquaintance) \\
& Kayleigh (friend or acquaintance) \\
Independently discovered parkrun and attended first & Robert (friend or acquaintance) \\
event with family member & Richard (spouse) \\
& Emily (spouse) \\
\hline Initial parkrun attendance not facilitated by existing & Hazel (spouse) \\
social relations & Kerry \\
& Julia \\
& Craig \\
\hline
\end{tabular}

